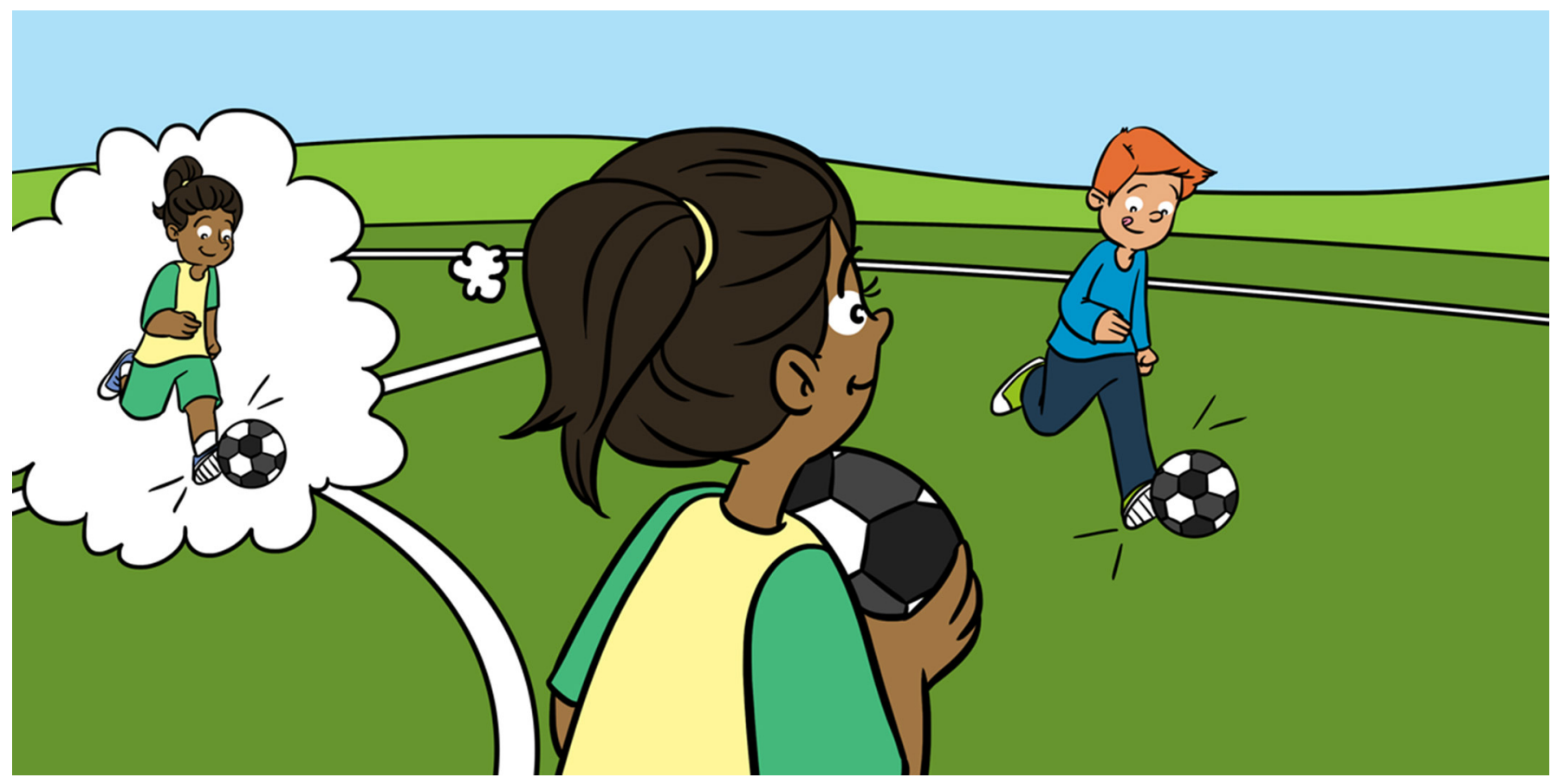

\title{
|MAGINE THAT! MENTAL TRAINING FOR CHILDREN WITH DEVELOPMENTAL COORDINATION DISORDER
}

\section{Matthew W. Scott ${ }^{1 *}$, Greg Wood ${ }^{2}$, Paul S. Holmes ${ }^{1}$, Ben Marshall ${ }^{2}$, Jacqueline Williams ${ }^{3}$ and David J. Wright ${ }^{1^{*}}$}

${ }^{1}$ Department of Psychology, Manchester Metropolitan University, Manchester, United Kingdom

${ }^{2}$ Department of Sport and Exercise Sciences, Manchester Metropolitan University, Manchester, United Kingdom

${ }^{3}$ Institute of Heath and Sport, Victoria University, Melbourne, VIC, Australia

YOUNG REVIEWERS:

THE TI

SUMMER

INTERNS

AGES: 14-16
Movement is important for children's health and well-being. Most children find it easy to learn to move but children with developmental coordination disorder (DCD) find it hard. It can be tricky for them to plan and control their movements. DCD affects 1 in every 20 children. It makes important tasks difficult, like getting dressed or playing games and sports. Scientists have found that children with DCD have different activity in some brain areas compared to other children. Mental training can increase activity in these areas of the brain. One type of mental training is motor imagery, which involves imagining doing movements. Another type of mental training is action observation, which involves carefully watching how people make certain movements. These techniques can help children with DCD get better at moving. This means that doing mental training might help make life easier for children with DCD. 
DEVELOPMENTAL COORDINATION DISORDER

A medical condition that makes it difficult for people to plan and control movements.
INTERNAL MODEL

A mental picture of what a movement should look like and feel like when we do it well.

\section{WHAT IS DEVELOPMENTAL COORDINATION DISORDER?}

Think about a time when you reached for something, maybe a cup of juice, and knocked it over! Although you had probably made this movement successfully many times before, sometimes movements do not turn out as we planned. This is rare for most of us, but it is a daily problem for children with developmental coordination disorder (DCD). DCD is a medical condition that makes it difficult for children to learn to move skillfully. Their movements look clumsy, and they often make mistakes. DCD is usually diagnosed in children between ages $5-8$, and it affects 1 in every 20 children. That means, on average, one child in every school class may have DCD-so it might even affect someone you know. DCD causes big problems for these children. They find it hard to do everyday tasks like feeding themselves or getting dressed, which can be very frustrating for them. They also struggle with playground games and sports, as they are not able to move as well as other children their age. This means they often also struggle to make friends or to do well in school. These things make day-to-day life more difficult for children with DCD. The good news is that scientists are starting to understand what causes DCD. They are also finding ways to help children with DCD to move better.

\section{WHAT CAUSES DCD?}

Scientists do not yet know the exact cause of DCD. Research using brain scanning techniques is starting to indicate why DCD might occur. Scientists have shown that children with DCD have different brain activity than children without DCD [1]. There are three main brain areas involved in movement, which are less active in children with DCD (Figure 1) [1]. The first area is an area across the center of the brain that helps to plan and prepare movements. The second area is more toward the front of the brain and is involved in copying and imagining movement. The third area is at the back of the brain and helps us to coordinate our movements. The lower activity in these areas might explain why children with DCD struggle to perform everyday movements.

We learn important movements, such as throwing, catching, or kicking, through practice. As we practice, we build up a picture in our minds about how the movement should look and feel when we do it well. We then use the picture to help us plan how to do the movement. We learn by comparing how the movement looks and feels against the mental picture. If the movement matches the picture, we know we did it right. If it does not match, we know we did it wrong and can try to correct it. Scientists call this picture an internal model. Scientists think that children with DCD might struggle with movements because they cannot create an internal model as they practice. This makes it hard for them to plan movements because they do not know how the 
Figure 1

Brain areas that are important for movement but are less active in children with DCD. (1) The precentral gyrus (green) helps to plan and prepare movement. (2) The inferior frontal gyrus (red) is involved in copying and imagining movement. (3) The cerebellum (gray) helps coordinate movements.

\section{MOTOR IMAGERY}

Imagining how performing a movement would look and feel.

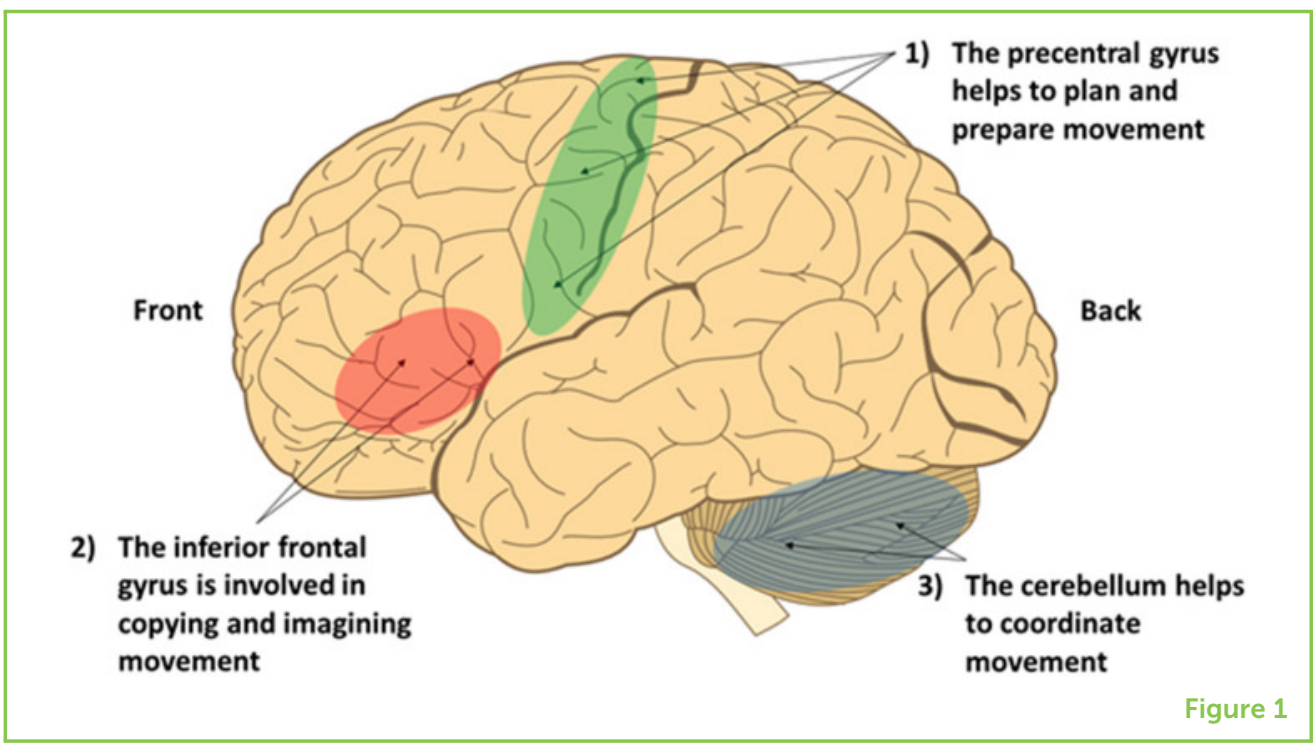

movements should look or feel. This means that they do not know if they are doing a movement correctly, and so they struggle to improve. The brain areas shown in Figure 1 are believed to help create internal models as we practice [1]. This could explain why children with DCD have less activity in these brain areas.

\section{CAN DCD BE TREATED?}

Children with DCD may face difficulties all their lives, so they must learn to live with them. They might adapt tasks to make life easier. For example, they may use Velcro-strap shoes to avoid tying laces, or they might avoid wearing certain shirts because they struggle to fasten the buttons. They might even completely avoid doing certain activities. For example, they may skip P.E. lessons in school, or avoid taking part in playground games and sports teams. This is a problem, because regular exercise is important for physical and mental health. The good news is that, once it has been diagnosed, children with DCD can be helped to improve their movement skills. Current techniques focus on doing repetitive physical practice. Therapists may ask children with DCD to repeat movements over and over again. To help the children, therapists might make tasks easier or split them up into smaller parts. However, scientists have suggested that just practicing movements is not enough to help children with DCD to improve. Instead, mental training that targets the less-active brain regions could be helpful [1].

\section{CAN MENTAL TRAINING HELP CHILDREN WITH DCD?}

Scientists believe that mental training techniques can help children with DCD. One mental training technique that can improve movement is called motor imagery. Motor imagery involves imagining 


\section{ACTION}

OBSERVATION

Watching people perform movements, either on video or in live demonstrations.

COMBINED ACTION OBSERVATION AND MOTOR IMAGERY (AOMI)

Watching a video of a movement while at the same time imagining the feeling of performing the movement movements, encouraging people to imagine both how a movement should look and how a movement should feel. You could try it yourself. Choose an object near you, reach for the object, grasp it, and bring it back toward you. Think about what you see and how the movement feels. Were there any sounds you heard as you moved? Now, without moving, imagine seeing your hand and arm reach and grasp the object, and imagine the feelings and sounds of doing it. That is motor imagery! Scientists in Australia have shown that motor imagery training can help children with DCD (aged 7-12) improve their movements [2]. The scientists asked one group to imagine and then practice doing movements like catching a ball, several times over 5 weeks. Children who did this motor imagery improved more than other groups that just did physical practice, or that did no training. But why does motor imagery work? Well, when we do motor imagery, the brain areas shown in Figure 1 are all more active [3]! Since these brain areas are less active in children with DCD, motor imagery helps to activate them. By doing motor imagery to activate these brain areas on a regular basis, children with DCD might be able to improve their movements.

Although motor imagery helps, it is not easy for children with DCD to imagine how a movement looks and feels. In fact, many children with DCD struggle to imagine themselves doing movements [2]. Scientists are investigating ways to help make motor imagery easier for these children. One way to help is by showing them movements. Watching movement is called action observation. Think about when you are in a P.E. lesson. You often watch your teacher do a movement and then copy it. This activates similar areas of the brain to motor imagery. For example, children with DCD could be given a video showing them what the movement should look like and asked to imagine the feelings of doing the movement at the same time (Figure 2). This is a bit like watching your favorite soccer player taking a penalty kick on television, while trying to imagine that you are the one kicking the ball and scoring the winning goal! Scientists call this combined action observation and motor imagery (AOMI) [3]. Doing AOMI means children with DCD do not have to imagine what the movement looks like because it is shown to them on video. This should make it easier, as they only need to imagine the feeling of the movement whilst they watch the video. Scientists have started to investigate brain activity when people do AOMI, and guess what? It causes more activity in the brain areas involved in movement than just doing motor imagery [3]! For this reason, $\mathrm{AOMI}$ might be better than motor imagery alone for improving movement in children with DCD.

Scientists in the UK have started to research whether AOMI can help children with DCD to move better. One study looked at how well children with DCD (aged 7-12) could copy the movements of another person, and they found that AOMI improved their ability to copy [4]. AOMI was even more helpful than motor imagery! This means that AOMI may help these children learn movements more easily when copying demonstrations. Other scientists have shown that AOMI can 
Figure 2

Combined action observation and motor imagery (AOMI) involves watching a video of a movement (such as kicking a ball) and, at the same, time imagining the feeling of doing that movement.

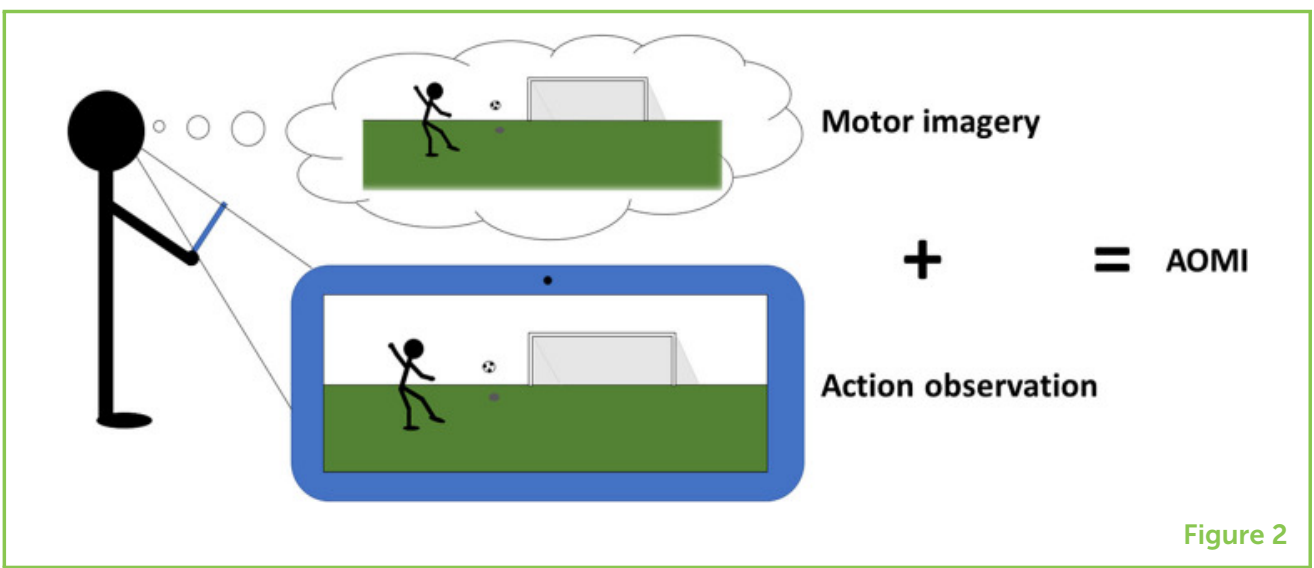

help children with DCD (aged 7-11) to learn quicker and to move their hands and eyes more skillfully [5]. These two experiments are the first to show that AOMI can help children with DCD to get better at planning and controlling their movements. In both experiments, improvements were found after only one session of repeated $\mathrm{AOMI}$ practice. As $\mathrm{AOMI}$ involves watching how the movement should look whilst imagining how the movement should feel, it might help children with DCD to develop an internal model that they can use to help them improve their movements $[4,5]$. Current research is trying to find out exactly how effective $A O M I$ can be in helping children with DCD to get better at everyday movements.

\section{CONCLUSION}

DCD is a complex medical disorder that can make everyday movements difficult and frustrating for many children. Although the cause is not fully known, science is helping us to understand the role of brain activity in DCD. Motor imagery can help children with DCD to improve their movements, but more recent research shows us that combining imagery with action observation may be even better. Scientists are now hopeful that AOMI can support children with DCD to move better, helping them to perform their daily activities more easily, and improving their quality of life.

\section{ACKNOWLEDGMENTS}

This work was supported by a Child Development Fund Research Grant from the Waterloo Foundation (Ref no. 2268-3968).

\section{REFERENCES}

1. Brown-Lum, M., and Zwicker, J. G. 2017. Neuroimaging and occupational therapy: bridging the gap to advance rehabilitation in developmental 
coordination disorder. J. Motor Behav. 49:98-110. doi: 10.1080/00222895. 2016.1271295

2. Wilson, P. H., Adams, I. L., Caeyenberghs, K., Thomas, P., Smits-Engelsman, B., and Steenbergen, B. 2016. Motor imagery training enhances motor skill in children with DCD: a replication study. Res. Dev. Disabil. 57:54-62. doi: 10.1016/j.ridd.2016.06.014

3. Eaves, D. L., Riach, M., Holmes, P. S., and Wright, D. J. 2016. Motor imagery during action observation: a brief review of evidence, theory and future research opportunities. Front. Neurosci. 10:514. doi: 10.3389/fnins.2016.00514

4. Scott, M. W., Emerson, J. R., Dixon, J., Tayler, M. A., and Eaves, D. L. 2020. Motor imagery during action observation enhances imitation of everyday rhythmical actions in children with and without developmental coordination disorder. Human Movement Sci. 71:102620. doi: 10.1016/j.humov.2020.102620

5. Marshall, B., Wright, D. J., Holmes, P. S., Williams, J., and Wood, G. 2020. Combined action observation and motor imagery facilitates visuomotor adaptation in children with developmental coordination disorder. Res. Dev. Disabil. 98:103570. doi: 10.1016/j.ridd.2019.103570

SUBMITTED: 15 December 2020; ACCEPTED: 18 November 2021; PUBLISHED ONLINE: 10 December 2021.

EDITED BY: Daniel F. Hermens, University of the Sunshine Coast, Australia

CITATION: Scott MW, Wood G, Holmes PS, Marshall B, Williams J and Wright D (2021) Imagine That! Mental Training for Children With Developmental Coordination Disorder. Front. Young Minds 9:642053. doi: 10.3389/frym.2021. 642053

CONFLICT OF INTEREST: The authors declare that the research was conducted in the absence of any commercial or financial relationships that could be construed as a potential conflict of interest.

COPYRIGHT @ 2021 Scott, Wood, Holmes, Marshall, Williams and Wright. This is an open-access article distributed under the terms of the Creative Commons Attribution License (CC BY). The use, distribution or reproduction in other forums is permitted, provided the original author(s) and the copyright owner(s) are credited and that the original publication in this journal is cited, in accordance with accepted academic practice. No use, distribution or reproduction is permitted which does not comply with these terms.

\section{YOUNG REVIEWERS}

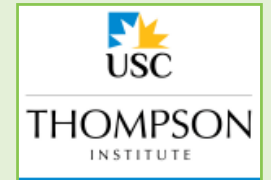

Summer Interns

\section{THE TI SUMMER INTERNS, AGES: 14-16}

We are Belle, Brodi, Emma, Isobel, Leah, Ella, and Grace. We are a group of high school students from different schools across the Sunshine Coast participating in a Summer Internship at the Thompson Institute. We all have an interest in Science and in particular Mental Health and Neuroscience, and enjoy learning more about these topics by reading the articles in Frontiers for Young Minds. We enjoy collaborating with researchers to help them better understand the adolescent experience. We 

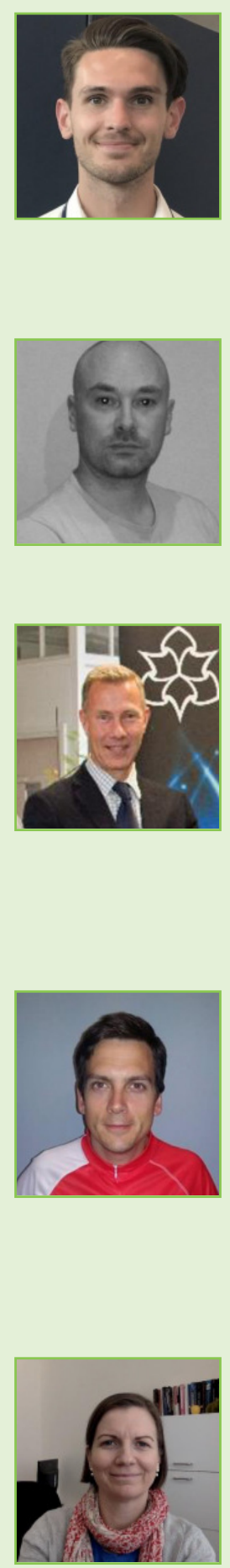

were helped to review this article by researchers from the Thompson Institute while participating in the Summer Internship.

\section{AUTHORS}

\section{MATTHEW W. SCOTT}

I am a postdoctoral research associate at Manchester Metropolitan University. I completed my Ph.D. at Teesside University in 2020. My previous research investigated the effects of combined action observation and motor imagery (AOMI) on imitation in children with and without developmental coordination disorder (DCD). I am now continuing to research the benefits of AOMI for children with $D C D$ and how best to improve daily activities for this population. ${ }^{*}$ m.scott@mmu.ac.uk

\section{GREG WOOD}

I am a senior lecturer in motor control and learning at Manchester Metropolitan University. I completed my Ph.D. in 2011, which looked at anxiety, eye movements, and performance of footballers. My research now focuses on vision in sport and people with movement problems. I am very interested in issues related to developmental coordination disorder and hand amputation.

\section{PAUL S. HOLMES}

I am a professor of motor cognition and deputy pro-vice chancellor in the Faculty of Health and Education at Manchester Metropolitan University. My research interests include motor cognition in human performance and movement rehabilitation. I have published widely, focusing on motor imagery and action-observation mechanisms. I have also worked as a sport psychologist in high-performance sport and have traveled with teams from Great Britain and England to major championships across the world.

\section{BEN MARSHALL}

I am a lecturer in sport and exercise psychology at Manchester Metropolitan University. I completed a Ph.D. in 2019, which investigated how combined action observation and motor imagery can be used to improve the hand-eye coordination of children with developmental coordination disorder. I am now interested in researching how we can use virtual reality to improve combined action observation and motor imagery interventions. In my spare time, I like cycling in the beautiful countryside near my home (when it is not raining).

\section{JACQUELINE WILLIAMS}

I am an associate professor from Victoria University in Melbourne, Australia. In my research, I work to understand the impact of developmental coordination disorder on children and their families. I work to develop strategies to reduce the impact of DCD and I engage with teachers, doctors, and occupational therapists, as well as the wider community, to raise awareness of DCD and its impact. Away from work, I enjoy exercising and spending time with my young children, and I love to sit with a cup of tea and a good book. 


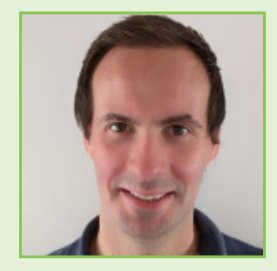

\section{DAVID J. WRIGHT}

I am a senior lecturer in psychology at Manchester Metropolitan University. My research focuses on two mental training techniques called action observation and motor imagery. I am interested in the brain activity when people do these techniques, as well as how they can be used to help people improve their movement skills. I am currently exploring how combined action observation and motor imagery interventions can help children with developmental coordination disorder learn how to perform everyday movement tasks. When I am not working, I enjoy spending time with my wife and two young children, running, and riding my bike. *d.j.wright@mmu.ac.uk 